\title{
Parental Monitoring: A Process Model of Parent-Adolescent Interaction
}

\author{
Louise Hayes, Alan Hudson and Jan Matthews \\ RMIT University, Australia
}

\begin{abstract}
Empirical evidence supports parental monitoring as a moderator of adolescent problem behaviours. A methodological review shows that monitoring has been measured using selfreport questions based on parental knowledge of adolescent free-time use; however, inconsistencies in the definition of monitoring have created confusion. A process model of parental monitoring is proposed. This proposed model conceptualises monitoring interactions in a temporal sequence. It proposes that parental monitoring occurs in two distinct stages: before the adolescent goes out and when they return home. Parental and adolescent responses to monitoring interactions impact on future monitoring episodes. The proposed model demonstrates that a functional understanding of parent and adolescent monitoring behaviours is essential to clinical prevention and intervention.
\end{abstract}

P arents of young children usually monitor their child's behaviour through direct observation. In contrast, the independence-seeking behaviour, of adolescence requires that parents monitor using indirect methods, which usually involves verbal rules for curfews or acceptable behaviour, and/or questions about where they have been. Parental monitoring is the widely accepted hypothetical construct used when explaining the parenting behaviours, knowledge, or attitudes that can influence adolescent use of free time. In the seminal work of Patterson and colleagues in the Oregon Youth Study, poor parental monitoring was linked to adolescent problem behaviour (Capaldi \& Patterson, 1989; Patterson \& Bank, 1987; Patterson, Bank, \& Stoolmiller, 1990; Patterson, Capaldi, \& Bank, 1991; Patterson, DeBaryshe, \& Ramsey, 1989; Patterson, Reid, \& Dishion, 1992; Patterson \& Yoerger, 1997). Subsequent studies have also supported the importance of parental monitoring as a moderator of problem behaviour in adolescents (Ary, Duncan, Biglan et al., 1999; Ary, Duncan, Duncan, \& Hops, 1999; Barnes,
Reifman, Farrell, \& Dintcheff, 2000; Barnes, Welte, Hoffman, \& Dintcheff, 1999; Chilcoat \& Anthony, 1996; Chilcoat, Breslau, \& Anthony, 1996; Kim, Hetherington, \& Reiss, 1999; Li, Feigelman, \& Stanton, 2000; Li, Stanton, \& Feigelman, 2000).

This paper begins with an overview of the research findings to date. Following this, methodological issues are examined which highlight two key methodological problems: (a) the operational definitions and measurement of parental monitoring, and (b) the generalisation of monitoring research. The review argues that although parental monitoring is conceptualised as one construct it has been operationalised in two ways, either as a parental management variable or as a parental knowledge variable. Put simply, research has measured what parents do to influence their adolescent's free time, or what parents know about their adolescent's free time, and both are purported to be parental monitoring. Finally, this paper proposes an alternative model of parental monitoring that is grounded in a behaviour analysis framework. The proposed model aims to

Address for correspondence Louise Hayes, Department of Psychology and Disability Studies, RMIT University, PO Box, 71, Bundoora, VIC 3083, Australia.Email louisehayes@vtown.com.au 
operationalise the interactive process of parental monitoring. This is necessary because clinical family interventions increasingly include instruction in parental monitoring as a component. The advice generally given to parents is that they must increase their monitoring. Increased monitoring is thought to occur when parents ask more questions about adolescent activities. While this makes intuitive sense, there are no studies demonstrating that more vigilant questioning is an effective parental monitoring strategy. An alternative explanation is theoretically plausible; increased parental questioning could lead to increases in conflict or an escalation of problem behaviour. The proposed process model of parental monitoring provides a theoretical foundation for exploring monitoring interactions and a basis for developing measures for clinical change.

\section{Parental Monitoring Research to Date}

\section{Foundational Parental Monitoring Research}

Patterson and colleagues (Capaldi \& Patterson, 1989; Patterson et al., 1992) developed parental monitoring as a latent construct in the Oregon Youth Study (OYS). There were two elements used to identify the construct. First, the network of rules and expectations parents have concerning the amount of information they require from their adolescent; and second, how much time the adolescent is with their parents (Capaldi \& Patterson, 1989). Parental monitoring was conceptualised as broader than the term supervision, because supervision is narrowly defined as the presence or absence of an adult (Dishion \& McMahon, 1998). Using this broad definition the OYS research consistently demonstrated that poor parental monitoring has a direct relationship to child and adolescent antisocial behaviour, and is correlated with other behavioural problems such as substance abuse and low self-esteem (Dishion \& Andrews, 1995; Dishion \& McMahon, 1998; Patterson, 1995; Patterson et al., 1992; Patterson \& Yoerger, 1997).

An explanation of the theoretical foundations of the OYS will give clarity to their development of the parental monitoring construct. The aim of the OYS study was to explain the development and maintenance of antisocial behaviour using social learning principles. Behaviour was explained within the three-term behaviour contingency (A-B-C) framework; where antecedents (stimuli or environmental cues) elicit a behavioural response, and the consequences of that response determine the predictability of the response in future interactions (Hudson, 1998). The central tenet of the OYS research was Patterson's (1982) coercion model of aversive family exchanges. The coercion model demonstrated that child problem behaviours begin with a breakdown of parental effectiveness, with disciplinary confrontations resulting in increased coercive exchanges between the child and parents. Consequently, the child finds that aversive behaviours such as whining, crying, yelling, hitting, or having tantrums are effective in turning off the aversive disciplinary behaviour of parents. In this way, the child trains the parents to use reactions that will terminate unpleasant parental behaviour. The coercion model demonstrated that analysis of daily parent-adolescent interactions at a microsocial level could elucidate the reinforcing contingencies that maintain problem behaviour. It was argued that small everyday events provide the key to understanding how behaviours are elicited, maintained, and organized (Andrews \& Dishion, 1994).

On the strength and consistency of the OYS research, it seems clear that the parental monitoring construct must be defined and measured at the microsocial level. To clarify the construct definition, Dishion and McMahon (1998) recently proposed that parental monitoring is best seen as a broad construct with the following definition: parental awareness of the child's activities and communication to the child that the parent is concerned about, and aware of, the child's activities. Therefore, it is the pattern of interaction between the parents and adolescent that is essential to our understanding of the development and maintenance of poor parental monitoring. Unfortunately, the following review of subsequent research indicates parental monitoring has become removed from this microsocial framework. 


\section{Subsequent Parental Monitoring Research}

Following the OYS research, the parental monitoring construct has gained increasing importance in studies of child and adolescent problem behaviour. Linear data modelling research (Ary, Duncan, Biglan et al., 1999; Ary, Duncan, Duncan et al., 1999; Barnes et al., 2000; Kim et al., 1999; Metzler, Noell, Biglan, Ary, \& Smolkowski, 1994) has consistently shown parental monitoring to be a moderator for a wide range of behaviours including antisocial behaviour, drug taking, early initiation of sexual activity, contraceptive use and safe sex practices. Longitudinal research (Barnes et al., 2000; Barnes et al., 1999; Chilcoat \& Anthony, 1996) has shown the predictive power of monitoring. Higher parental monitoring was associated with a 2-year delay in the onset of drug use, when measured in a 4-year study that began with middle childhood, ages $8-10$ years (Chilcoat \& Anthony, 1996). In this study, youths who were in the highest quartile for parental monitoring showed a 2-year delay in the onset of drug use when compared with youths in the lowest parental monitoring quartile. Further, Barnes and colleagues $(2000 ; 1999)$ used a 6-wave longitudinal study, and found high parental monitoring diminished the upward trajectory of alcohol misuse across adolescence.

These impressive results show that parental monitoring is a crucial factor in the development of adolescent problem behaviour. The results were consistent with the OYS research results, yet comparisons reveal the definition and measurement of parental monitoring were different in these subsequent studies. In these subsequent studies, parental monitoring is best defined with the phrase "does the parent usually know where the child is", and self-report questions of retrospective parental knowledge were used to measure it. In contrast, the OYS researchers sought to explicate the rules and expectation parents have, the amount of information they require, and the time shared between parent and adolescent. The narrower definition used in the subsequent research indicates recent studies have not conceptualised the parental monitoring construct in the same manner as Patterson and colleagues. Despite the differences in definition, this narrower parental monitoring construct is also seen as a critical parenting factor in the development of problem behaviour.

\section{Monitoring Redefined as Knowledge}

Recently, Stattin and Kerr (Kerr \& Stattin, 2000; Kerr, Stattin, \& Trost, 1999; Stattin \& Kerr, 2000) proposed an alternative definition of monitoring. They argue that parental monitoring measures have actually been measuring parental knowledge of adolescent activity, rather than parental tracking and supervision efforts. Stattin and Kerr propose that this knowledge depends on an adolescent's willingness to disclose information to parents. In a series of self-report studies, their questionnaires found three factors were important to parental monitoring knowledge: child disclosure (children spontaneously telling parents what they have been doing); parental solicitation (parents asking children what they have been doing); and parental control (rules and limit setting). This research found that the most important contributor to parental monitoring knowledge was child disclosure. Parental solicitation was associated with higher, not lower, problem behaviour. Stattin and Kerr (2000) called for a reinterpretation of parental monitoring as parental monitoring knowledge, and this rests on an understanding of the factors that determine child disclosure, not parental activity.

\section{Methodological Issues Arising from Research}

An examination of the research previously summarised indicates there are two key methodological issues that need closer investigation. The key issues are (a) the definition and measurement of parental monitoring, and (b) the generalization of research findings, and further discussion on each follows.

\section{Definition and Measurement}

Patterson and colleagues (Capaldi \& Patterson, 1989; Patterson et al., 1992) tried various methods of measuring parental monitoring, including a parental questionnaire, interviews with fathers 
and mothers, repeated parent telephone interviews, repeated child telephone interviews, and a difference score which compared parent and child reports. The measures assessed parental awareness, or knowledge, of the child's activities, as well as time spent with the child. From all these measures, only three were considered satisfactory and retained in the OYS. The strongest indicator was an interviewer's answer to the global score "did the child seem well supervised by the parents" (Patterson et al., 1992). This global interviewer's rating on how well the family monitored their child contributed most to the parental monitoring construct, with a regression weight of .93 , compared with child report at .50 and parent report at .17 . The other two indicators retained were a structured telephone interview administered separately to the child, and another to the parent. Patterson et al. reported the psychometric status of the parental report was poor, but was retained in order to meet their multi-agent and multimethod standards.

One would expect future studies refining the parental monitoring measure would have followed. Unfortunately, subsequent studies have seemingly ignored the measurement difficulty reported by Capaldi and Patterson (1989). Most research has taken only the self-report questions that tapped into parental knowledge of activity, and administered them using a self-report questionnaire to parents and/or adolescents. Across the 38 studies reviewed in this research where parental monitoring was a key variable, only four studies have reported alternatives to self report questionnaires, and these will be expanded on later (Crouter, Helms-Erikson, Updegraff, \& McHale, 1999; Crouter, MacDermid, McHale, \& Perry-Jenkins, 1990; Kilgore, Snyder, \& Lentz, 2000; Pettit, Bates, Dodge, \& Meecel, 1999).

The majority of parental monitoring questionnaires comprise two to eight questions. An examination of the question content reveals ambiguity is possible in participant interpretations. A hypothetical example will help to clarify the interpretation dilemma. Consider three different adolescents who are asked the most common parental monitoring question, "Do your parents usually know where you are after school?" Adolescent $A, B$ and $C$ all responded with the same answer (almost always) and they all score 4 points on a Likert scale. On questioning further, we find major differences in attitude and family standards have influenced the answers. The parents of Adolescent $A$ know he is "hanging out" at the shops, but they are comfortable with that; they have a "boys will be boys" attitude. The parents of Adolescent B know she tries to hang out at the shops, but she is not allowed, and there has been family conflict about it. Finally, the parents of Adolescent $C$ know where he is because they have clear rules forbidding him from hanging out at the shops and a parent directly supervises his free time on most days. We can see in this example, all the parents know where their adolescent is, and they all scored 4 points on the questionnaire. Nevertheless, each adolescent is monitored differently, and most practitioners would agree that Adolescent $A$ is poorly monitored. This example demonstrates that asking questions about monitoring, without asking about family beliefs, social cognitions, and norms for acceptable behaviour is problematic.

Parental monitoring self-reports of this type measure perceptions, not behaviour. Selfenhancing bias and social desirability could alter parental reports of monitoring. Patterson et al. (1992) demonstrated this effect by comparing behavioural observations to self-report data. They reported that there is generally little correlation between what parents say they do and what they actually do. Parental reports of their own monitoring are generally higher than adolescent reports, and the data range is restricted. Therefore, we must assume most parents will report they know where their adolescents are, and are likely to be reluctant to admit it if they do not. To overcome this dilemma many studies have questioned adolescents on monitoring, rather than parents. Adolescent self-reports are usually considered more accurate than parental reports, but they are a measure of adolescent perceptions of parental knowledge rather than actual parenting behaviour, and can harbour negative attribution biases. That is, where an adolescent is experiencing family problems they may also report negative attitudes to parental monitoring. For example, they may report their 
parents do not care enough to monitor, or report their parents are too strict.

There are few examples in the literature of alternatives to retrospective self-report methods. Behavioural observations, or prospective recording studies are needed to enhance the self-report data. One study of time sampling using retrospective 15-minute interval time activity schedules has shown adolescents spend an average of $22.5 \%$ of their time without adult supervision (Pettit et al., 1999). While this study did not elaborate on how parents monitor this free time, further research using such methods could shed light on parental use of rules and indirect parenting strategies. Crouter and colleagues (Crouter \& Head, 2002; Crouter et al., 1999; Crouter et al., 1990) have conducted a series of studies using repeated telephone interviews to parents and children, to measure parental monitoring knowledge. They found parental monitoring knowledge differs as a function of mother's work involvement, child sex and birth order, child's personal characteristics, and parental qualities (Crouter et al., 1999). Clearly, more research that goes beyond monitoring knowledge of activities and demonstrates how rules, behavioural contingencies, communication, and relationship quality can influence adolescent free time is necessary.

\section{Generalisation of Parental Monitoring Research}

Usually in parental monitoring research, monitoring is measured among high-risk groups. While this is not surprising, given the focus on resolving adolescent problem behaviours, it does make generalisations problematic. The parental monitoring construct evolved from research that aimed to reduce or prevent antisocial behaviours and substance abuse in adolescents, and therefore, participants were selected from high-risk families. Boys were the primary participants in several high profile studies (Barnes et al., 1999; Brendgen, Vitaro, \& Tremblay, 2001; Dishion, Patterson, Stoolmiller, \& Skinner, 1991; Patterson et al., 1992; Wasserman, Miller, Pinner, \& Jaramillo, 1996). Participants have also been selected from clinical populations including adolescents from an anti smoking program (Ary, Duncan, Biglan et al.,
1999), and an adolescent sex clinic (DiClemente et al., 2001). Recently, studies have focused on exclusively African-American populations (Colder, Mott, Levy, \& Flay, 2000; DiClemente et al., 2001; Li, Feigelman et al., 2000; Li, Stanton et al., 2000), or AfricanAmerican/Hispanic samples (Dutra et al., 2000; Forehand, Miller, Dutra, \& Chance, 1997; Wasserman et al., 1996). While there is a large body of research on specific subgroups, caution should be exercised when making generalisations from this research.

\section{Summary of Monitoring Research and Methodology}

In summary, the research has consistently demonstrated a relationship between parental monitoring and adolescent problem behaviours. Longitudinal studies have shown parental monitoring remains stable over time (Barnes et al., 2000; Barnes et al., 1999; Chilcoat \& Anthony, 1996). However, the narrow self-report methodologies have limited the research, tapping only into parental monitoring awareness or adolescent perceptions of monitoring. Many studies have used high risk or culturally specific participants, making our understanding of generalised parental monitoring vague. Researchers have only just begun to report normative monitoring data (Crouter et al., 1999; Crouter et al., 1990; Kerr \& Stattin, 2000; Kerr et al., 1999). The next step in monitoring research is to test alternative methodologies with normative samples. This may provide information relevant to prevention and parent education programs.

\section{A Process Model of Parental Monitoring}

This paper has argued that the recent lack of clarity surrounding the parental monitoring construct is a consequence of narrow or different research definitions and measurement. Shown in this section is a proposed process model of parental monitoring. Where traditional models of parental monitoring tap only knowledge or supervision behaviours, this proposed model incorporates all of the elements of parent-adolescent interactions that relate to monitoring. The central tenet is that parental monitoring is a 
complex interactive process between parents, adolescents, and their environment, and must be assessed at micro and macro social levels. The process model comprises (a) an assessment of parent and adolescent behaviour, (b) hypotheses about the function of this behaviour and its cyclical process, (c) an evaluation of the parental characteristics that contribute to monitoring interactions, (d) an evaluation of the adolescent characteristics that contribute, and finally (e) consideration of the interplay of family context, peers, school, and community. We argue that parental monitoring is a dynamic process and the proposed process model represents this.

\section{Assessment of Monitoring Behaviours}

The proposed parental monitoring process model is based on social learning principles and uses a behaviour analysis framework to interpret the functional importance of monitoring interactions. The behaviour analysis approach argues that an examination of the antecedents and consequences of behaviour provide an explanation of the reinforcement contingencies, thereby providing understanding of why behaviours are repeated.

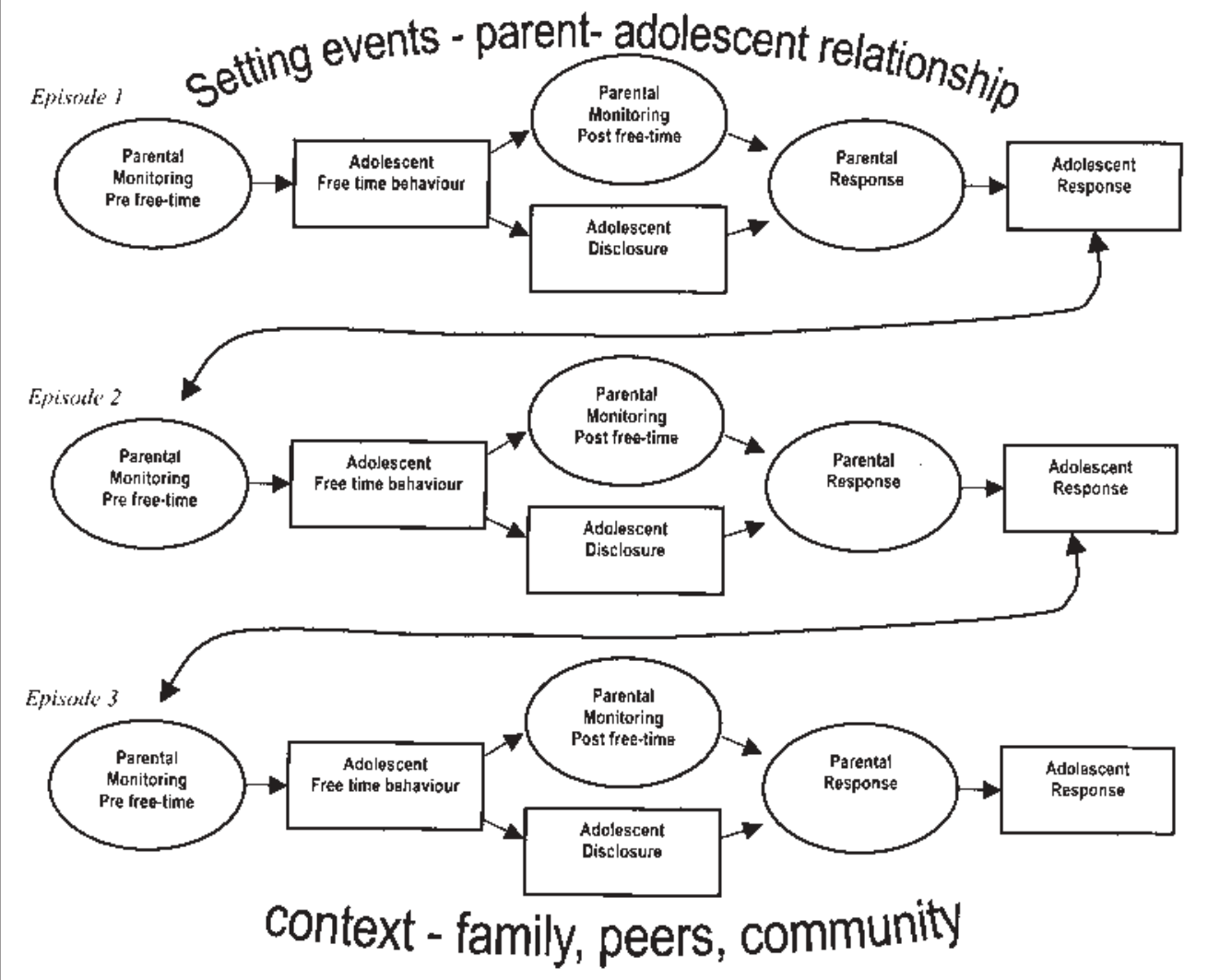

FIGURE 1

Process model of parental monitoring. 
The proposed process model is depicted in Figure 1 and shows a series of parental monitoring episodes, each in temporal sequence. In the proposed model, parenting behaviour is represented by ellipses and adolescent behaviour is represented by rectangles. This is because the behaviour of parents may have different functions to the behaviour of adolescent, and they must be analysed separately. A monitoring sequence is explained by following Episode 1 from left to right. Pre free-time monitoring represents the parenting behaviour that occurs before adolescents go out. Pre free-time monitoring behaviours include parents making enquiries about where adolescents are going and what they plan to do, giving permission, finding out about peers, and setting limits and curfews. The next step shows the adolescent free-time behaviour, this is time away from parents and may include being supervised by another adult (a friend's parents) or may be with no adult supervision. The next phase shows what occurs when the adolescent returns home, and this has two elements. The adolescent can tell his parents what he has been doing (represented as disclosure), or his parents can solicit the information by questioning (represented as post free-time monitoring). Thus, post freetime monitoring behaviour is the soliciting of information from adolescents about their activities, whereas adolescent disclosure is when adolescents freely discuss what they have been doing. The willingness of an adolescent to disclose their activity has been shown as a critical factor to parental monitoring (Kerr et al., 1999). The proposed process model demonstrates that both disclosure and post free-time monitoring contribute to the parental response, which would cover the full gamut of possible parental responses, from expressing an opinion, delivering consequences, or yelling and lecturing. The adolescent response could be acquiescence or defiance, but their response is influenced by parental responses toward their independence.

\section{Developing an Understanding of the Function of Monitoring Behaviours and their Evolution}

The next step in understanding monitoring is critical; this is to consider the functional relation- ship of the behaviours and the changes throughout adolescent development. The proposed process model shows that each monitoring episode influences future parental monitoring behaviours and adolescent behaviours. Utilising Patterson's (1982) coercive family process model it is evident that monitoring behaviours would be developed and maintained within the wellrehearsed action reaction sequence of the parent and adolescent interactions. It is expected that positive behaviours, such as disclosure and communication, will reinforce parental monitoring, and patterns of avoidance and escalation will contribute to poorer monitoring. It is hypothesized that where problem behaviours have become "hot issues", the coercive process is likely to be performed many times in parental monitoring interactions.

Clearly, avoidance and escalation are key research areas for understanding poor parental monitoring. An understanding of normal parent-adolescent conflict in monitoring, compared with clinical levels of conflict, is needed. Using the proposed process model of monitoring we can see that advising parents to change one element of behaviour only, for example increasing post free-time monitoring (asking their adolescent more questions), is unlikely to have the desired impact and improve monitoring. Instead, the reverse may occur where increased questioning leads to greater conflict and poorer monitoring. Normative data shows adolescents report an average of seven disagreements per day, mostly with mothers (Laursen \& Collins, 1994). With non-clinical families, parent-adolescent conflicts are usually about daily activities or chores and are often unresolved. Meta-analytic results report low-level compromise in parent-adolescent conflict, with submission and disengagement prevalent (Laursen \& Collins, 1994). Formoso, Gonzales and Aiken (2000) found that high parental monitoring attenuated the relationship between conflict and conduct disorder for girls, but exacerbated it for boys. In high conflict homes, boys with high parental monitoring exhibited a stronger relationship between conflict and conduct disorder. Formoso et al., while acknowledging that these findings need replication, suggest parental monitoring may be protective 
for girls living in high conflict homes, but a risk factor for boys. Therefore, it appears that parent-adolescent monitoring dialogue is likely to be frequent, with opposing views, and often unresolved. However, high or very low levels of conflict in parental monitoring interactions are likely to be indicators of clinical importance.

Pre free-time monitoring and post free-time monitoring are verbal behaviours that parents use to influence the behaviour of adolescents. Parents need to ask questions and give adolescents rules to follow. The principles of rule governed behaviour suggest effective rule following is more probable when rules are clear and consequence dependent (Skinner, 1969), and coercive exchanges are more likely when rules are unclear (Patterson et al., 1992). Malott (1989) argues that effective rules are direct acting, and have contingencies that are immediate, probable or sizeable. In parental monitoring for example, a rule with a direct acting consequence, "come home straight from school and you can go to a friend's house at 5 o'clock", provides a clear and immediate consequence for appropriate behaviour. Parental monitoring based on direct-acting rules should theoretically have a powerful effect on adolescent and parenting behaviours, providing the consequences are consistently applied. Alternatively, rules that have indirect acting consequences are likely to have little influence in modifying adolescent behaviour because a strong immediate positive reinforcer like "hanging out with friends", outweighs competing weaker negative reinforcement like "avoiding a lecture from parents". Adolescents are keenly aware of parental styles and become skilled at weighing up the consequences of following or breaking parental rules. Further, the strong reinforcement from peers for inappropriate behaviour can make choices about parental approved behaviour more difficult for some adolescents. Research on effective monitoring rules in the pre free-time and post freetime stages is required.

\section{The Contribution of Parental Characteristics}

A social interactional model of parenting by Dishion and McMahon (1998) provides a useful foundation for explaining how parental charac- teristics contribute to monitoring. Dishion and McMahon propose that parental monitoring can be conceptualised within a triadic model of parenting that describes the interrelations of parenting: (a) motivation, which represents the parent's belief system and includes norms, values and goals; (b) parental monitoring; and (c) behaviour management, which is active parental attempts to shape outcomes by using incentives, reinforcement, limit setting and negotiation. The foundation of this model is the parent-child relationship. This parenting model shows that parental monitoring is embedded within relationship quality, parenting motivations, goals and values, and the behaviour management skills, within the social context of the family (Dishion \& McMahon, 1998).

When the parent-adolescent relationship quality is poor, the process of monitoring is likely to be so coercive that parents may avoid monitoring interactions. Patterson et al. (1992) reported that when parents' efforts to monitor have been repeatedly defeated by their child, any attempt to improve monitoring is often met with intense resistance. By way of contrast, unattached parents were too busy with their own lives to monitor their adolescents and resisted monitoring interventions (Patterson et al., 1992). We can see that an assessment of monitoring demands an assessment of parent-adolescent relationships. Where the relationship is poor, the first step in improving monitoring would be rebuilding parent-adolescent relationships, rather than suggesting parents elicit information about their adolescent's activities. Again, the emphasis in parenting literature to have parents "know where your child is" should be implemented with caution and awareness that this could increase aversive exchanges and resistance from adolescents and parents, leading to more unsupervised time.

\section{The Developing Adolescent's Contribution}

An evaluation of monitoring also demands consideration of the adolescent contribution to the interaction. While an expectation that "difficult adolescents are normal" has become endemic in our society, it is not supported in research. Transformation, rather than storm and stress, is 
a more apt way of defining adolescence (Larson, Richards, Moneta, Holmbeck, \& Duckett, 1996). Just how monitoring is involved in the transformation from parental control to adolescent independence is untested. However, adolescent emotional experience of the family is shown to follow a curvilinear path (Larson et al., 1996). Early adolescents report less positive family interactions and view their families as less friendly, whereas older adolescents report more favourable and positive family emotions.

A dramatic drop in the amount of time family members spend together has been observed during adolescence (Larson et al., 1996). In early adolescence, family time is replaced with time alone, rather than time spent out of the home, and in later adolescence the decline is moderated by increased opportunities outside the home, rather than family conflict (Larson et al., 1996). Limited research has investigated the conditions and ages under which parents increase freedom (Bumpus, Crouter, \& McHale, 2001; Steinberg \& Silverberg, 1986). A comparison of parental and adolescent views on appropriate ages to grant autonomy found parents and adolescents varied by 14 months in their estimates (Hudson, Bell, Hudson, \& Houndoulesi, 1986). For example, the age at which boys should "decide when to come home at night" according to parents is 17.2 years, yet boys reported 15.6 years was the appropriate age. Therefore, the crucial time for vigilant monitoring coincides with early adolescence, when perceptions of family interactions are most strained, and adolescents are yearning for time away from the family.

\section{Monitoring Within the Social Context}

Finally, this proposed process model shows that parent-adolescent monitoring interactions are further influenced by contextual factors. Important factors include extended family, siblings, family support, peers, school, community, cultural, socioeconomic and geographical area. Research has shown an important relationship between contextual factors and monitoring. For example, Patterson and Dishion (1985) report that poor monitoring in adolescence increases the likelihood of deviant peer associa- tions. Unsupervised peer contact in the afterschool hours is a risk factor in the development of externalising problems (Pettit et al., 1999). Recent longitudinal studies using multitrait multimethod analyses show that high parental monitoring is preceded by proactive parenting and an advantageous family ecology (Pettit, Laird, Dodge, Bates, \& Criss, 2001). Patterson et al. (1992) reported that clinical therapists in the Oregon Youth Study found their sample of families were continually faced with problems such as job loss, stress and poverty, and the effects of context were impossible to exclude from the analyses. It is likely, when parents or adolescents are questioned about monitoring, their perceptions are framed within their context. Therefore, while research shows parents have the greatest influence on the adolescent free time use, the mediating role of peers and the community must be important considerations.

\section{Conclusion and Future Implications}

The research clearly demonstrates when parents know where adolescents are and what they are doing, the adolescents are less likely to behave delinquently. However, there is no evidence to show that translating these research results into parental counsel to "know where your kids are" will have the expected positive effect. The consistent findings on the significance of poor monitoring are important, but limited by problematic definitions and narrow methods of measurement.

A model of parental monitoring was proposed which suggests future research must explore the temporal sequence of monitoring interactions. Monitoring behaviours were classified across this temporal sequence, demonstrating that monitoring is an interactive process, and it evolves alongside adolescent development. It was argued that monitoring interactions in adolescence will remain consistent with established A-B-C behaviour chains. Where coercive interactions are present, increased questioning by parents may increase coercive exchanges and avoidance. Additionally, in adolescence, parental monitoring becomes indirect and is maintained using verbal rules. Parents and adolescents views on autonomy are important aspects of the monitoring process, although they 
are also likely to differ in their expectations of autonomy. Finally, research indicates low-level conflict is typical; therefore, the process model proposed that conflict is likely to influence future monitoring interactions.

Initial tests of the proposed model, testing data modelling of the pre free-time and post freetime monitoring behaviours are currently underway. We anticipate that normative data from a large sample may be necessary to provide comparisons of pre free-time monitoring and post free-time monitoring behaviours. If normative data on typically functioning families is available, it is anticipated that this may be compared with clinical families, and differences in parent-adolescent monitoring interactions elicited. Overall, the aim of future research is to operationalise monitoring behaviours, and in this way clarify the relevance of parental monitoring behaviours, when compared with monitoring knowledge of activity.

We propose that future monitoring research adopt a constructional approach, with the goal being to explain and contrast good parental monitoring behaviours with poor monitoring, then use this knowledge to develop appropriate intervention strategies. Clinicians require sound evidence on how they can implement monitoring changes in families who are demonstrating poor monitoring skills. Ultimately, at the universal level, parents of young adolescents would benefit from education on the most effective way to monitor their adolescents, as they make the transition to secondary school and independent behaviour. The proposed model suggests education for parents may need to include pre freetime monitoring behaviours, for example, setting limits and rules; and education should also cover post free-time monitoring behaviours, for example, parental knowledge acquisition and encouraging disclosure. In this way, parental monitoring research may provide educational information to parents and professionals on appropriate ways to nurture and respond to adolescents as they push parental boundaries.

\section{References}

Andrews, D.W., \& Dishion, T.J. (1994). The microsocial structure: Underpinnings of adolescent problem behaviour. In R.D. Ketterlinus \& M.E.
Lamb (Eds.), Adolescent problem behaviours (pp. 187-207). Hillsdale, New Jersey: Lawrence Erlbaum Associates.

Ary, D.V., Duncan, T.E., Biglan, A., Metzler, C.W., Noell, J.W., Smolkowski, K. (1999). Development of adolescent problem behavior. Abnormal Child Psychology, 27(2), 217-230.

Ary, D.V., Duncan, T.E., Duncan, S.C., \& Hops, H. (1999). Adolescent problem behavior: The influence of parents and peers. Behaviour Research and Therapy, 37(3), 217-230.

Barnes, G.M., Reifman, A.S., Farrell, M.P., \& Dintcheff, B.A. (2000). The effects of parenting on the development of adolescent alcohol misuse: A six-wave latent growth model. Journal of Marriage and Family, 62(1), 175-186.

Barnes, G.M., Welte, J.W., Hoffman, J.H., \& Dintcheff, B.A. (1999). Gambling and alcohol use among youth: Influences of demographic, socialization, and individual factors. Addictive Behavior, 24(6), 749-767.

Brendgen, M., Vitaro, F., \& Tremblay, R.E.L.F. (2001). Reactive and proactive aggression: Predictions to physical violence in different contexts and moderating effects of parental monitoring and caregiving behaviour. Journal of Abnormal Child Psychology, 29(4), 293-304.

Bumpus, M.F., Crouter, A.C., \& McHale, S.M. (2001). Parental autonomy granting during adolescence: Exploring gender differences in context. Developmental Psychology, 37(2), 163-173.

Capaldi, D.M., \& Patterson, G.R. (1989). Psychometric properties of fourteen latent constructs from the Oregon Youth Study. New York: Springer-Verlag.

Chilcoat, H.D., \& Anthony, J.C. (1996). Impact of parent monitoring on initiation of drug use through late childhood. Journal of American Academy of Child and Adolescent Psychiatry, 35(1), 91-100.

Chilcoat, H.D., Breslau, N., \& Anthony, J.C. (1996). Potential barriers to parent monitoring: Social disadvantage, marital status, and maternal psychiatric disorder. Journal of American Academy of Child and Adolescent Psychiatry, 35(12), 1573-1682.

Colder, C.R., Mott, J., Levy, S., \& Flay, B. (2000). The relation of perceived neighborhood danger to childhood aggression: A test of mediating mechanisms. American Journal of Community Psychology, 28(1), 83-103.

Crouter, A.C., \& Head, M.R. (2002). Parental monitoring and knowledge of children. In M. H. Bornstein (Ed.), Handbook of parenting Vol. 3 Being and becoming a parent (2nd ed., pp. 461-483). Mahwah, NJ: Lawrence Erlbaum Associates, Publishers.

Crouter, A.C., Helms-Erikson, H., Updegraff, K., \& McHale, S.M. (1999). Conditions underlying parents' knowledge about children's daily lives in middle childhood: Between-and within-family comparisons. Child Development, 70(1), 246-259. 
Crouter, A.C., MacDermid, S.M., McHale, S.M., \& Perry-Jenkins, M. (1990). Parental monitoring and perceptions of children's school performance and conduct in dual- and single-earner families. Developmental Psychology, 26(4), 649-657.

DiClemente, R.J., Wingwood, G.M., Crosby, R., Sionean, C., Cobb, B.K., Harrington, K., et al. (2001). Parental monitoring: Association with adolescents' risk behaviors. Pediatrics, 107(6), 1363-1368.

Dishion, T.J., \& Andrews, D.W. (1995). Preventing escalation in problem behaviors with high-risk young adolescents: Immediate and 1-year outcomes. Journal of Consulting and Clinical Psychology, 63(2), 538-548.

Dishion, T.J., \& McMahon, R.J. (1998). Parental monitoring and the prevention of child and adolescent problem behavior: A conceptual and empirical formulation. Clinical Child and Family Psychology Review, 1(1), 61-75.

Dishion, T.J., Patterson, G.R., Stoolmiller, M., \& Skinner, M.L. (1991). Family, school, and behavioral antecedents to early adolescent involvement with antisocial peers. Developmental Psychology, 27(1), 172-180.

Dutra, R., Forehand, R., Armistead, L., Brody, G., Morse, E., Morse, P.S., et al. (2000). Child resiliency in inner-city families affected with HIV: The role of family variables. Behaviour Research and Therapy, 38, 471-486.

Forehand, R., Miller, K.S., Dutra, R., \& Chance, M.W. (1997). Role of parenting in adolescent deviant behavior: Replication across and within two ethnic groups. Journal of Consulting and Clinical Psychology, 65, 1036-1041.

Formoso, D., Gonzales, N.A., \& Aiken, L.S. (2000). Family conflict and children's internalizing and externalizing behavior: Protective factors. American Journal of Community Psychology, 28(2), 175-199.

Hudson, A. (1998). Applied behaviour analysis. In A. Bellack, M. Hersen \& T. Ollendick (Eds.), Comprehensive clinical psychology (Children and adolescents: Clinical formulation and treatment ed., Vol. 5, pp. 107-129). New York: Pergamon.

Hudson, A., Bell, W., Hudson, T., \& Houndoulesi, V. (1986). The views of parents and adolescents on the granting of behavioural autonomy to adolescents: Some normative data. The Australian Educational and Developmental Psychologist, 3(2), 6-11.

Kerr, M., \& Stattin, H. (2000). What parents know, how they know it, and several forms of adolescent adjustment: Further support for a reinterpretation of monitoring. Developmental Psychology, 36(3), 366-380.

Kerr, M., Stattin, H., \& Trost, K. (1999). To know you is to trust you: Parents' trust is rooted in child disclosure of information. Journal of Adolescent Health, 22(6), 737-752.

Kilgore, K., Snyder, J., \& Lentz, C. (2000). The contribution of parental discipline, parental monitoring, and school risk to early-onset conduct problems in African American boys and girls. Developmental Psychology, 36(6), 835-845.

Kim, J.E., Hetherington, E.M., \& Reiss, D. (1999). Associations among family relationships, antisocial peers, and adolescent externalizing behaviors: Gender and family type differences. Child Development, 70, 1209-1230.

Larson, R.W., Richards, M.H., Moneta, G., Holmbeck, G., \& Duckett, E. (1996). Changes in adolescents' daily interactions with their families from ages 10 to 18: Disengagement and transformation. Developmental Psychology, 32(4), 744-754.

Laursen, B., \& Collins, W.A. (1994). Interpersonal conflict during adolescence. Psychological Bulletin, 115(2), 197-209.

Li, X., Feigelman, S., \& Stanton, B. (2000). Perceived parental monitoring and health risk behaviors among urban low-income African-American children and adolescents. Journal of Adolescent Health, 27(1), 43-48.

Li, X., Stanton, B., \& Feigelman, S. (2000). Impact of perceived parental monitoring on adolescent risk behavior over 4 years. Journal of Adolescent Health, 27(1), 49-56.

Malott, R.W. (1989). The achievement of evasive goals: Control by rules describing contingencies that are not direct acting. In S.C. Hayes (Ed.), Rule-governed behavior Cognition, contingencies, and instructional control (pp. 269-322). New York: Plenum Press.

Metzler, C.W., Noell, J., Biglan, A., Ary, D., \& Smolkowski, K. (1994). The social context for risky sexual behavior among adolescents. Journal of Behavioral Medicine, 17(4), 419-438.

Patterson, G.R. (1982). Coercive family process. Eugene, OR: Castalia.

Patterson, G.R. (1995). Coercion as a basis for early age of onset for arrest. In J. McCord (Ed.), Coercion and punishment in long-term perspectives (pp. 81-105). Cambridge: Cambridge University Press.

Patterson, G.R., \& Bank, L. (1987). When is a nomological network a construct? In D.R. Peterson \& D.B. Fishman (Eds.), Assessment for decision (pp. 249-279). New Brunswick NJ: Rutgers University Press.

Patterson, G.R., Bank, L., \& Stoolmiller, M. (1990). The preadolescent's contributions to disrupted family process. In R. Montemayor, G.R. Adams \& T.P. Gullotta (Eds.), From childhood to adolescence A transitional period? (pp. 107-133). Newbury Park CA: Sage.

Patterson, G.R., Capaldi, D., \& Bank, L. (1991). An early starter model for predicting delinquency. In D.J. Pepler \& K.H. Rubin (Eds.), The development and treatment of childhood aggression (pp. 139-168). New Jersey: Laurence Erlbaum. 
Patterson, G.R., DeBaryshe, B.D., \& Ramsey, E.A. (1989). A developmental perspective on antisocial behavior. American Psychologist, 44(2), 329-335.

Patterson, G.R., \& Dishion, T.J. (1985). Contributions of families and peers to delinquency. Criminology, 23(1), 63-79.

Patterson, G.R., Reid, J.B., \& Dishion, T.J. (1992). Antisocial boys. A social interactional approach $V$. 4. Eugene OR: Castalia.

Patterson, G.R., \& Yoerger, K. (1997). A developmental model for late-onset delinquency. Lincoln: University of Nebraska Press.

Pettit, G.S., Bates, J.E., Dodge, K.A., \& Meecel, D.W. (1999). The impact of after-school peer contact on early adolescent externalizing problems is moderated by parental monitoring, perceived neighborhood safety and prior adjustment. Child Development, 70(5), 768-778.
Pettit, G.S., Laird, R.D., Dodge, K.A., Bates, J.E., \& Criss, M.M. (2001). Antecedents and behavior problem outcomes of parental monitoring and psychological control in early adolescence. Child Development, 72(2), 583-598.

Skinner, B.F. (1969). Contingencies of reinforcement A theoretical analysis. Englewood Cliffs $\mathrm{NJ}$ : Prentice-Hall.

Stattin, H., \& Kerr, M. (2000). Parental monitoring: A reinterpretation. Child Development, 71(4), 1072-1085.

Steinberg, \& Silverberg. (1986). The vicissitudes of autonomy in early adolescence. Child Development, 57(4), 841-851.

Wasserman, G.A., Miller, L.S., Pinner, E., \& Jaramillo, B. (1996). Parenting predictors of early conduct problems in urban, high risk boys. Journal of American Academy of Child and Adolescent Psychiatry, 35(9), 1227-1236. 